\title{
Area disadvantage, socioeconomic position and women's contraception use: a multilevel study in the UK
}

\author{
Rebecca Bentley, Anne Kavanagh, Anthony Smith
}

\begin{abstract}
Background and methodology This study aimed to investigate associations between area-level socioeconomic disadvantage (central heating, car ownership and residents in professional occupations), individual-level socioeconomic position (social class and educational qualifications) and contraception use in the UK for the period 1990-1991. Multilevel logistic regression analysis was conducted on cross-sectional data from the National Survey of Attitudes and Lifestyles of 9793 women, 16-59 years of age, residing in 646 postcode districts throughout the UK.
\end{abstract}

Results Women with lower levels of formal education were less likely to use contraception than women with higher education [odds ratio (OR) $0.50,95 \% \mathrm{Cl}$ $0.44-0.57]$. Women in the middle and low social class groups were less likely to use contraception than women in the higher social class group (OR $0.84,95 \% \mathrm{Cl}$ $0.74-0.97$ and OR $0.66,95 \% \mathrm{Cl} 0.56-0.79$, respectively). The association between social class and contraception use varied significantly across postcode districts $(p<0.001)$. The contraception use of women in the lowest social class group varied the most geographically. Women in the lowest quintiles of disadvantage were less likely to use contraception than women in the most advantaged quintiles according to all three measures, namely central heating (OR $0.76,95 \% \mathrm{Cl} 0.61-0.94$ ), car ownership (OR $0.67,95 \% \mathrm{Cl} 0.53-0.84)$ and residents in professional occupations (OR $0.75,95 \% \mathrm{Cl} 0.61-0.93$ ).

Discussion and conclusion Although more information is needed to understand how area and individual socioeconomic characteristics are associated with contraceptive use, this study suggests that policy on contraceptive use needs to be extended beyond individually targeted approaches and needs to take into account socioeconomic determinants of contraceptive use.

Keywords area disadvantage, contraception use, multilevel analysis, socioeconomic position

J Fam Pann Reprod Health Care 2009; 35(4): 221-226

(Accepted 12 June 2009)

\section{Introduction}

Area disadvantage and socioeconomic position (SEP) are strongly associated with a number of health-related practices such as smoking, physical activity and diet. ${ }^{1-8}$ While there is a large literature on the association between socioeconomic characteristics of areas and contraception use in developing countries, ${ }^{9-20}$ the authors are not aware of comparable studies that examine women's contraception use across their reproductive years in higher income countries such as the UK. Furthermore, only a small number of studies have assessed the role of individual SEP (such as education, social class and occupation) on contraception use in high-income countries. ${ }^{21-23}$ In order to estimate both individual and area socioeconomic influences on contraceptive use and assess geographic variation in likelihood of contraception use, multilevel analysis is the most appropriate analytical technique as it allows simultaneous examination of individual and arealevel variation in individual outcomes. ${ }^{24-26}$

In the USA, multilevel analysis of associations between various neighbourhood-level measures of socioeconomic context and birth control used by adolescents found females in neighbourhoods with more 'idle youth' (i.e. persons aged 16-19 years who were not in school or the armed forces, not high school graduates and not in the

Key Centre for Women's Health in Society, The University of Melbourne, Melbourne, Australia

Rebecca Bentley, BBSc, PhD, Research Fellow

Anne Kavanagh, BMBS, PhD, Professor and Head of Centre

Australian Research Centre in Sex, Health \& Society, La Trobe University, Melbourne, Australia

Anthony Smith, BSc, PhD, Professor and Principal Research Fellow

Correspondence to: Dr Rebecca Bentley, Key Centre for Women's Health in Society, The University of Melbourne, Victoria 3010,

Australia. E-mail: brj@unimelb.edu.au
Key message points

- This multilevel analysis of contraception use in the UK provides evidence that area disadvantage is associated with a decreased likelihood of contraception use.

- Individual socioeconomic position is strongly associated with the likelihood of contraception use and this relationship varies geographically, particularly for low social class groups.

- Policy on contraceptive use needs to comprise both individually targeted approaches and approaches that take into account broader social, economic and cultura determinants of contraceptive use.

labour force) were more likely to report that they did not use contraception at first or most recent sexual intercourse compared with females in neighbourhoods with lower concentrations of 'idle youth'. ${ }^{27}$

In the UK, wide geographical variations in patterns of teenage pregnancies have been observed, with higher pregnancy rates found in more deprived areas and the proportion of conceptions ending in abortion higher in more affluent areas. ${ }^{28,29}$ Differences in rates of teenage pregnancy between more affluent and deprived areas in Scotland widened from the 1980 s to the 1990 s. $^{30}$ These area differences in pregnancy rates suggest variation in contraception use and sexual activity amongst teenagers across the UK; so much so that in 1999 the Teenage Pregnancy Strategy was introduced across 148 geographic areas (local top-tier authorities) with funding allocated according to conception rates. 31 This government initiative aimed to reduce teenage conceptions and lessen the risk of long-term social exclusion of teenage parents from educational, employment and other opportunities. ${ }^{32}$ The policy succeeded in reducing conceptions in teenage populations, particularly in strategically-targeted areas, 31 and changing patterns of use of contraceptive services by the targeted group. 33 
Although there has been no multilevel analysis of contraceptive use in the UK, there have been some multilevel analyses of teenage conception rates. Diamond et al. ${ }^{34}$ found that area-level deprivation was associated with increased rates of conception and that access to specialised young people's family planning clinics was associated with reduced rates of conception; a relationship that was less strong in rural areas. However, Diamond et al. were only able to adjust for age at the individual level and it is highly likely that observed associations between area deprivation and contraceptive use are confounded by the socioeconomic characteristics of teenagers and/or their families. Nonetheless it is possible that contraception use varies geographically across the UK for all adult women of reproductive age due to a range of factors such as area differences in distance and access to services; the sociodemographic and socioeconomic population profiles of areas; and the socioeconomic resources of areas. This has important implications for policy and clinical practice. Policy, while implemented on a geographical basis in the case of the Teenage Pregnancy Strategy, has targeted a particular group and disparities in contraception use might occur across all reproductive ages. Understanding how contraception use varies by area-based and individual socioeconomic disadvantage potentially reiterates for clinicians the broader context for how the contraceptive needs of some groups might not be being met.

In this article we describe the first multilevel analysis of area disadvantage, SEP and contraceptive use in a highincome setting of women aged 16-59 years using the National Survey of Sexual Attitudes and Lifestyles (NATSAL). Specifically we address the following four research questions:

1 Is there significant variation between postcode districts in contraceptive use, before and after adjustment for individual characteristics?

2 Is individual SEP (social class and education) an important determinant of contraceptive use?

3 Does the effect of SEP on contraceptive use vary between postcode districts?

4 Does area socioeconomic disadvantage influence contraceptive use?

\section{Methods}

\section{Sample areas and population}

The NATSAL survey was obtained from The Data Archive, University of Essex in Colchester, UK. A total of 18876 people participated in the survey between May 1990 and December 1991 (63\% response rate). ${ }^{35}$

A multistage stratified design was used whereby households were randomly selected from the Post Office Small Users Postcode Address File (PAF) - chosen over other options because of its superior coverage of residential addresses in the UK. ${ }^{36}$ The PAF was used to select 50010 addresses from which 29802 were potentially eligible. Addresses ruled as ineligible were non-residential, residential but empty, demolished or not yet built. Additionally, some residents were classed as not eligible if no one in the household was within the specified age range (16-59 years). ${ }^{36}$

Electoral wards were used at the primary sampling units, selected from a list stratified by region, population density and housing tenure profile. One thousand were selected and 50 addresses were selected from each of these. ${ }^{36}$

A respondent who was aged between 16 and 59 years was randomly selected from within each household using a method based on the generation of random numbers.

Face-to-face interviews were used because of the complexity of the data sought, the need for careful definition of terms, extensive filtering, the high number of people without telephones and the absence of an efficient telephone sampling method. 36

Around $57 \%$ of survey participants were women $(n=$ 10758 ). We excluded women who did not respond to the question on contraceptive use (1.9\% of the sample), and to ensure heterogeneity in contraception use we excluded a further $3.5 \%$ of women who resided in a postcode district where fewer than five women were sampled.

Analysis was conducted with and without women whose sexual activity in the past year was not known $(3 \%$ of remaining analytical sample). As there were no differences between models, results are reported here for models excluding this group. The total number of women included in our analysis was 9793.

Women excluded from the analysis for the reasons outlined above were older (i.e. more likely to be in the $45-59$ year age group, $p<0.001)$, more likely to be religious and attend church services ( $p<0.001$ for both) and have less formal education $(p<0.001)$ (results not shown). Social class was not different for women excluded from the analysis compared with women remaining in the analytical sample.

\section{Ethical approval}

This study was approved by the La Trobe University Faculty of Health Sciences, Faculty Human Ethics Committee (Reference Number FHE01/092).

\section{Analytical structure}

Data were analysed according to the hierarchical multilevel structure of 9793 women aged 16-59 years at level 1 nested within 646 postcode districts at level 2. Each postcode district had between 5 and 69 women, with a mean of 9.4 women per postcode district. Postcode districts were selected as the geographical unit of analysis because they were the smallest unit into which the survey participants could be divided and smaller spatial units are likely to uncover stronger contextual effects. ${ }^{37}$

\section{Outcome variable}

The response was binary (yes/no) indicating women's contraception use in the past year based on the survey question that asked respondents to indicate whether they had used contraception in the previous year and, if so, to specify the type of method from a list including the pill, coil/intrauterine device (IUD), condom, cap, foam tablets/jellies etc., sponge, douching, safe period, withdrawal, sterilisation-female, vasectomy, abstinence, other method. Respondents could select more than one method.

\section{Area level socioeconomic disadvantage}

Area level socioeconomic disadvantage was estimated from the 1991 Population Census of England, Scotland and Wales. ${ }^{38}$ Three indicators of area disadvantage were selected: proportion of residents within each postcode district from the highest socioeconomic group (SEG) (i.e. who were classified as being in professional occupations), proportion of households who did not own a car (NC) and proportion of households that had no central heating (NCH).

The first of these measures (SEG) was used as an indicator of the likely social and material resources of areas that are derived from having residents who are economically advantaged or being places where economically advantaged people reside. While most indicators of deprivation have measured the proportion of 
residents in the lowest rather than highest SEPs, we were also interested in resources professionals brought to areas (such as educational and occupational opportunities) or that attracted professionals to reside in areas (such as good quality health care services). Car ownership and central heating have been used in the UK in composite indicators of material deprivation. 39,40

Measures of area disadvantage were categorised into quintiles from the highest to lowest levels of area disadvantage. This enabled us to examine whether associations between area-disadvantage and contraceptive use were non-linear.

\section{Individual level variables}

\section{Measures of socioeconomic position}

The indicator of social class used in the NATSAL was an occupationally derived variable. The indicator included in these analyses was based on the highest social class ranking recorded within the household within which the respondent was resident. Household social class was selected over individual social class because women in the sample may have young children and, as a consequence, be at home or working reduced hours (i.e. be in part-time or casual employment), which is likely to affect their opportunities for advancement. Occupationally derived social class would not adequately reflect their social class status in these cases. ${ }^{41}$

Social class was classified as follows: I Professional (5.7\%), II Intermediate $(28.6 \%)$, IIIN skilled non-manual $(22.5 \%)$, IIIM skilled manual $(16.9 \%)$, IV partly skilled $(10.5 \%), \quad \mathrm{V}$ unskilled $(2.5 \%)$ and VI Armed forces/inadequately described/not classified (13.5\%). This was then collapsed into high (I, II), middle (IIIN, IIIM), and low (IV,V, VI) social class groups.

Respondent's highest educational qualification was classified in the survey as being either a degree, higher education or below degree level and Advanced level (Alevels) or equivalent, Ordinary levels (O-levels) or equivalent and Certificate of Secondary Education (CSE) or equivalent, foreign/other or none (not passed any formal examinations at the equivalent of the O-level/CSE-level).

Education was collapsed into higher (Degree, A-level, O-level) and lower (None, Foreign, Other) formal education with around $30 \%$ of women being in the lower category.

\section{Sociodemographic variables}

Selection of confounders was based on known determinants of contraception use that were also related to social class and area disadvantage in the UK.

Age group (16-24, 25-34, 35-44 and 45-59 years), ethnicity (White, Black, Asian, Other) and number of children at home were included in the model as sociodemographic control variables. We also controlled for religion (Roman Catholic or Muslim, Other), sexual activity in the past year (yes/no) and attendance at religious services (attended once a week or more, other).

\section{Analysis and modelling strategy}

A weighted multilevel logistic regression model with individuals at level 1 nested within postcode districts at level 2 was used to assess the likelihood of contraception use in the past year. The parameters of the multilevel model were estimated using MLWin 2.01 software $^{42}$ with a second-order penalised quasi likelihood RIGLS estimation method. ${ }^{43}$ In most cases the reference category was the most frequently occurring; however, in the case of social class, the high social class group was taken as a reference category to allow for the possibility of observing a gradient. Results are reported as odds ratios (OR) with a lower $95 \%$ confidence interval (LCI) and upper $95 \%$ confidence interval (UCI).

Model 1 was a two-level model with no covariates in the fixed part of the model (variance components model). This model was included to test for statistical significance of between-area variation in contraceptive use.

Model 2 was a two-level model adjusted for individuallevel covariates. This model was included to test if individual SEP was associated with contraceptive use. The association between social class and contraception use was adjusted for education, whereas the association between education and contraception use was not adjusted for social class as this occupationally derived measure temporally follows attainment of qualifications and is, therefore, unlikely to be a confounder of the association between education and contraception use.

Model 3 allowed the effect of social class to vary by postcode district. This model was included to test if the association between social class and contraception use varied by postcode district.

Model 4 included postcode district level variables indicating area disadvantage to test for contextual effects of area disadvantage. The association between each area-level measure and contraception use was tested as separate models.

\section{Results}

Of the 9793 women included in the analysis, 67\% stated that they had used contraception in the past year.

Table 1 shows the frequencies of contraceptive use by the individual-level covariates. Contraception use was lower for women who had lower levels of education $(56 \%)$, were in the lowest social class group $(57 \%)$, attended religious services once a week or more $(54 \%)$, had not had sex $(9 \%)$ and were over 45 years of age $(41 \%)$. Similarly, contraception use was lowest in the most disadvantaged

Table 1 Individual covariates by contraception use

\begin{tabular}{|c|c|c|}
\hline Covariates & $\begin{array}{l}\text { Prevalence of } \\
\text { contraception } \\
\text { use }(\%)\end{array}$ & $\begin{array}{l}\text { Total } \\
(n=9793)\end{array}$ \\
\hline \multicolumn{3}{|l|}{ Age group (years) } \\
\hline $16-24$ & 73.0 & 1751 \\
\hline $25-34$ & 82.0 & 3030 \\
\hline $35-44$ & 76.2 & 2383 \\
\hline $45-59$ & 41.0 & 2629 \\
\hline \multicolumn{3}{|l|}{ Indicator of sexual activity } \\
\hline $\begin{array}{l}\text { in past year } \\
\text { No }\end{array}$ & 8.7 & 1523 \\
\hline Yes & 78.9 & 8270 \\
\hline \multicolumn{3}{|l|}{ Number of children } \\
\hline None & 63.9 & 2911 \\
\hline One or more & 69.7 & 6882 \\
\hline \multicolumn{3}{|l|}{ Ethnicity } \\
\hline White & 68.3 & 9366 \\
\hline Black/Asian/Other & 62.1 & 427 \\
\hline \multicolumn{3}{|l|}{ Religion } \\
\hline None or Other & 68.4 & 8637 \\
\hline Roman Catholic or Muslim & 64.6 & 1156 \\
\hline \multicolumn{3}{|l|}{$\begin{array}{l}\text { Religious service attendance } \\
\text { (once per week or more) }\end{array}$} \\
\hline No & 69.7 & 8727 \\
\hline Yes & 54.1 & 1066 \\
\hline \multicolumn{3}{|l|}{ Education (highest qualification) } \\
\hline $\begin{array}{l}\text { Higher (Degree, A-level, } \\
\text { O-level) }\end{array}$ & 73.0 & 6890 \\
\hline Lower (None/Other) & 56.1 & 2903 \\
\hline \multicolumn{3}{|l|}{ Household social class } \\
\hline High social class & 74.0 & 3360 \\
\hline Middle social class & 70.2 & 3862 \\
\hline Low social class & 56.8 & 2571 \\
\hline
\end{tabular}


Table 2 Area disadvantage (quintiles) by contraception use

\begin{tabular}{lll}
\hline Covariates & $\begin{array}{l}\text { Prevalence of } \\
\text { contraception } \\
\text { use (\%) }\end{array}$ & $\begin{array}{l}\text { Total } \\
(\boldsymbol{n}=\mathbf{6 4 6})\end{array}$ \\
\hline Socioeconomic group (SEP)a & & \\
1 & 69.3 & 129 \\
2 & 66.6 & 131 \\
3 & 70.9 & 132 \\
4 & 69.8 & 133 \\
5 & 63.0 & 121 \\
No car (NC) ${ }^{\text {a }}$ & & \\
1 & 70.9 & 125 \\
2 & 68.6 & 130 \\
3 & 68.4 & 125 \\
4 & 65.1 & 142 \\
5 & 67.5 & 124 \\
No central heating (NCH) & & \\
1 & 70.1 & 138 \\
2 & 67.1 & 125 \\
3 & 70.9 & 132 \\
4 & 67.4 & 121 \\
5 & 63.5 & 130 \\
\hline
\end{tabular}

a1 = least disadvantaged; 5 = most disadvantaged.

areas for SEG, $\mathrm{NCH}$ and the second most disadvantaged for NC (Table 2).

\section{Model 1}

There was significant between-area variation in contraceptive use $(p<0.0001)$, with an overall estimated probability of contraceptive use of $70 \%$ (95\% CI 69-71) and range of contraception use between postcode districts of $52 \%$ to $80 \%$. Approximately $5 \%$ of the variation in contraception use in the null model (i.e. the model with no covariates included) was between postcode districts $(p<0.001)$.

\section{Model 2}

Both education and social class were strong predictors of contraceptive use. Women with low levels of formal education were much less likely to use contraception than women with middle or high levels of formal education (OR $0.50,95 \%$ CI $0.44-0.57$ ) and women in the middle and low social class groups were less likely to have used contraception than those in the high social class group (OR $0.84,95 \%$ CI $0.74-0.97$ and OR $0.66,95 \%$ CI $0.56-0.79$, respectively) (Table 3 ).

\section{Model 3}

Random coefficients were significant, indicating that the effect of social class varied across postcode districts in the UK $(p<0.001)$. This suggests an interaction between geographic areas and the association between social class and contraception use, particularly for low-social class groups who had the most variance between postcode districts (accounting for over 65\% of the total estimated variance).

\section{Model 4}

A significant contextual effect of postcode district level area disadvantage on contraception use was found after individual covariates and geographic variations in social class were included in the model (Table 4). For all three indicators, women living in the most disadvantaged quintiles were less likely to use contraception than women from the most advantaged quintile (OR $0.75,95 \% \mathrm{CI}$ $0.61-0.93$ for SEG, OR $0.67,95 \%$ CI $0.53-0.84$ for NC and OR $0.76,95 \%$ CI $0.61-0.94$ for $\mathrm{NCH}$ ). For $\mathrm{NCH}$, the probability of contraceptive use appeared to decrease (except of the most disadvantaged group) from the lowest proportion without central heating to highest while the associations between SEG and NC was not linear across the quintiles of disadvantage.

\section{Discussion}

This study has a number of important findings. First, there is substantial variation between areas in the prevalence of contraceptive use and the estimate of this variation remains significant even when adjustment is made for the socioeconomic and sociodemographic characteristics of individuals residing in each area. Second, we find that individual SEP is strongly associated with contraceptive use, with women with low levels of formal education or in the low or middle social class group being less likely to use contraception. Third, there is significant between-area variation in the effects of social class, with women in the lowest social class group having the greatest amount of variation in contraceptive use. Finally, area-level socioeconomic disadvantage is an important determinant of contraceptive use, with women in the lowest quintiles of disadvantage according to all three area-level measures (proportion of professional, households with no central heating and households with no car) being less likely to use contraception than women in the most advantaged quintiles.

Importantly, this study indicates contraception use is not equally distributed geographically across the UK. A large part of this variation is due to women's SEP and sociodemographic characteristics, but socioeconomic characteristics of areas are also important. In addition, we found evidence that the association between social class and contraception use varied geographically and there are small but significant contextual effects of area socioeconomic disadvantage.

Table 3 Model 2: odds ratios and 95\% confidence intervals for the association between social class, education and contraception use

\begin{tabular}{|c|c|c|c|c|c|c|}
\hline \multirow[t]{2}{*}{ Socioeconomic position } & \multicolumn{3}{|c|}{ Unadjusteda } & \multicolumn{3}{|c|}{ Adjustedb } \\
\hline & OR & LCl & $\mathrm{UCl}$ & OR & $\mathrm{LCl}$ & UCl \\
\hline \multicolumn{7}{|l|}{ Social class } \\
\hline High social class & 1.00 & & & 1.00 & & \\
\hline Middle social class & 0.73 & 0.65 & 0.83 & 0.84 & 0.74 & 0.97 \\
\hline Low social class & 0.33 & 0.28 & 0.38 & 0.66 & 0.56 & 0.79 \\
\hline \multicolumn{7}{|l|}{ Education } \\
\hline Higher (Degree, A-level, O-level) & 1.00 & & & 1.00 & & \\
\hline None/Other & 0.61 & 0.55 & 0.67 & 0.50 & 0.44 & 0.57 \\
\hline
\end{tabular}

aModels adjusted for age only.

bModels adjusted for age, ethnicity, religion, religious service attendance, number of children and sexual activity. Social class was additionally adjusted for education.

$\mathrm{LCl}$, lower confidence interval: OR, odds ratio; UCl, upper confidence interval. 
Table 4 Model 4: odds ratios and 95\% confidence intervals for area disadvantage variables

\begin{tabular}{|c|c|c|c|c|c|c|}
\hline \multirow[t]{2}{*}{ Quintiles } & \multicolumn{3}{|c|}{ Unadjusteda } & \multicolumn{3}{|c|}{ Adjusted ${ }^{b}$} \\
\hline & OR & LCl & $\mathrm{UCl}$ & OR & $\mathrm{LCl}$ & $\mathrm{UCl}$ \\
\hline \multicolumn{7}{|c|}{ Socioeconomic group (SEG)c } \\
\hline 1 & 1.00 & & & 1.00 & & \\
\hline 2 & 0.90 & 0.75 & 1.08 & 0.95 & 0.78 & 1.17 \\
\hline 3 & 1.02 & 0.84 & 1.24 & 1.13 & 0.85 & 1.49 \\
\hline 4 & 0.95 & 0.79 & 1.14 & 0.98 & 0.80 & 1.21 \\
\hline 5 & 0.68 & 0.56 & 0.81 & 0.75 & 0.61 & 0.93 \\
\hline \multicolumn{7}{|c|}{ No car $(\mathrm{NC})^{\mathrm{c}}$} \\
\hline 1 & 1.00 & & & 1.00 & & \\
\hline 2 & 0.79 & 0.65 & 0.94 & 0.73 & 0.59 & 0.90 \\
\hline 3 & 0.91 & 0.76 & 1.10 & 0.91 & 0.73 & 1.13 \\
\hline 4 & 0.76 & 0.63 & 0.91 & 0.86 & 0.69 & 1.07 \\
\hline 5 & 0.58 & 0.47 & 0.70 & 0.67 & 0.53 & 0.84 \\
\hline \multicolumn{7}{|c|}{ No central heating $(\mathrm{NCH})^{\mathrm{c}}$} \\
\hline 1 & 1.00 & & & 1.00 & & \\
\hline 2 & 0.83 & 0.69 & 1.00 & 0.83 & 0.67 & 1.02 \\
\hline 5 & 0.70 & 0.58 & 0.85 & 0.76 & 0.61 & 0.94 \\
\hline
\end{tabular}

aModels adjusted for age only.

bModels adjusted for age, ethnicity, religion, religious service attendance, number of children, sexual activity, education and social class. c1 = least disadvantaged; $5=$ most disadvantaged.

Additionally, the significance of associations between area disadvantage and contraceptive use (for all three indicators) suggests that there are structural or social aspects to more disadvantaged areas that may result in a lower likelihood of contraception use for women residing in them. This supports the argument that women's contraceptive behaviour is associated with the area in which they live in addition to their personal circumstances. Having established that area disadvantage is associated with contraception use, further research - perhaps of a more qualitative nature - is needed to ascertain how the socioeconomic characteristics of areas may create barriers to contraception use for some women. Also, the contribution of distance and access to services might also be considered as a determinant of contraception use in the UK. It is likely that some of the association between area disadvantage and contraception use evident in these analyses might be explained by geographic variation in service access and distance to services.

\section{Strengths and limitations}

This study is a large national study with multiple indicators of individual SEP and area disadvantage. It is the first of its type and has produced interesting findings about the associations between area disadvantage, SEP and contraception use and geographic variation in some of these relationships across the UK.

However, the analysis had a number of limitations. First, it was based on cross-sectional data, limiting our ability to make causal inferences. Second, postcode districts have been characterised by one dimension - area disadvantage, using relatively crude indicators. These indictors are proxies of socioeconomic disadvantage but they do not tell us what it is about these disadvantaged areas that make contraceptive use less likely. In addition, other area-level characteristics such as area-level social capital or access to services may be important. Third, we have relied on administrative units as our geographic units for analysis; they may not be the unit that corresponds to residents' own sense of place. ${ }^{44}$ This is likely to lead to more conservative estimates of associations. Fourth, these analyses are based on data collected in the early 1990s. They, therefore, provide baseline estimates of associations between area disadvantage, SEP and contraception use before policy initiatives introduced in the United Kingdom in 1999 that aimed to reduce teenage conception rates. ${ }^{31-33}$ As the NATSAL survey was repeated in 2000 and 2010, it would be valuable to explore if observed associations between area disadvantage, SEP and contraception use have changed - i.e. if policy that aimed to reduce conceptions specifically in teenage populations had wider impacts on contraception use in the general population of women. Fifth, as we have an overall measure of contraceptive use we do not know whether the area differences observed apply to particular methods of contraception use.

\section{Conclusions}

We have shown that in the UK contraceptive use is associated with individual SEP and area-level disadvantage and that there are statistically significant differences between areas in the use of contraception. Furthermore, we demonstrate that the association between social class and contraceptive use varies between areas, particularly for low social class groups. These findings suggest that both the socioeconomic characteristics of individuals and places are important determinants of contraceptive use. Policy on contraception use should take a broad perspective on factors associated with contraception use rather than be focused on single strategies such as increasing sexual education in target groups (such as teenagers) or increasing access to contraceptive technology.

\section{Disclaime}

The National Survey of Sexual Attitudes and Lifestyles dataset was obtained from the Data Archive at the University of Colchester, Colchester, UK. The copyright holder of the data, the original data producer, the relevant funding agencies and the data archive, bear no responsibility for their further analysis or interpretation.

\section{Statements on funding and competing interests}

Funding Rebecca Bentley was supported by a National Health and Medical Research Council (NHMRC) Capacity Building Grant, The Australian Health Inequities Program and an Australian Research Centre in Sex, Health and Society PhD Scholarship. Anthony Smith was supported by a VicHealth Senior Fellowship. Competing interests None identified.

\section{References}

1 Duncan C, Jones K, Moon G. Smoking and deprivation: are there neighbourhood effects? Soc Sci Med 1999; 48: 497-505.

2 Frohlich K, Potvin L, Gauvin L, Chabot P. Youth smoking 
initiation: disentangling context from composition. Health Place 2002; 8: 155-166.

3 Pinilla J, Gonzalez B, Barber P, Santana Y. Smoking in young adolescents: an approach with multilevel discrete choice models. J Epidemiol Community Health 2002; 56: 227.

4 Ross C. Walking, exercising, and smoking: does neighbourhood matter? Soc Sci Med 2000; 51: 265-274

5 Sooman A, Macintyre S, Anderson A. Scotland's Health - a more difficult challenge for some? The price and availability of healthy foods in socially contrasting localities in the West of Scotland. Health Bull 1993; 51: 276-284.

6 Sundquist J, Malmström, Johansson SE. Cardiovascular risk factors and the neighbourhood environment: a multilevel analysis. Int J Epidemiol 1999; 28: 841-845.

7 Twigg L, Moon G, Duncan C, Jones K. Consumed with worry: 'unsafe' alcohol consumption and self-reported problem drinking in England. Health Educ Res 2000; 15: 569-580.

8 Twigg L, Moon G, Jones K. Predicting small area health-related behaviour: a comparison of smoking and drinking indicators. Soc Sci Med 2000; 50: 1109-1120.

9 Ali MM. Quality of care and contraceptive pill discontinuation in rural Egypt. J Biosoc Sci 2001; 33: 161-172.

10 Ali M, Cleland J. Determinants of contraceptive discontinuation in six developing countries. J Biosoc Sci 1999; 31: 343-360.

11 Dang A. Differentials in contraceptive use and method choice in Vietnam. Int Fam Plann Perspect 1995; 21: 2-5.

12 DeGraff D, Bilsborrow R, Guilkey D. Community-level determinants of contraceptive use in the Philippines: a structural analysis. Demography 1997; 34: 385-398.

13 Dwivedi SN, Sundaram KR. Epidemiological models and related simulation results for understanding of contraceptive adoption in India. Int J Epidemiol 2000; 29: 300-307.

14 Entwhistle B, Rindfuss RR, Walsh SJ, Evans TP, Curran SR Geographic information systems, spatial network analysis and contraceptive choice. Demography 1997; 34: 171-187.

15 Entwisle B, Hermalin A, Kamnuansilpa P, Chamratrithirong A A multilevel model of family planning availability and contraceptive use in rural Thailand. Demography 1984; 21 559-574.

16 Entwisle B, Mason W. Multilevel effects of socioeconomic development and family planning programs on children ever born. Am J Sociol 1985; 91: 616-649.

17 Entwisle B, Mason WM, Hermalin Al. The multilevel dependence of contraceptive use on socioeconomic development and family planning program strength. Demography 1986; 23: 199-216.

18 Entwisle B, Rindfuss R, Guilkey D, Chamratrithirong A, Curran $S$, Sawangdcc $Y$. Community and contraceptive choice in rural Thailand: a case study of Nang Rong. Demography 1996; 33: $1-11$.

19 Kamal N, Sloggett A, Cleland JG. Area variations in use of modern contraception in rural Bangladesh: a multilevel analysis. J Biosoc Sci 1999; 31: 327-341.

20 Wong G, Mason W. The hierarchical logistic regression model for multilevel analysis. J Am Stat Assoc 1985; 80: 513-524.

21 Riphagen FE, Lehert P. A survey of contraception in five West European countries. J Biosoc Sci 1989; 21: 23-46.

22 Johnson A, Wadsworth J, Wellings K, Field J. Sexual Attitudes and Lifestyles. Oxford, UK: Blackwell Scientific Publications, 1994.

23 Spinelli A, Talamanca IF, Lauria L. Patterns of contraceptive use in 5 European countries. European Study Group on Infertility and Subfecundity. Am J Public Health 2000; 90: 1403-1408.
24 Diez-Roux AV. Multilevel analysis in public health research. Annu Rev Public Health 2000; 21: 171-192.

25 DiPrete T, Forristal J. Multilevel models: methods and substance. Annu Rev Sociol 1994; 20: 331-357.

26 Bullen N, Jones K, Duncan C. Modelling complexity: analysing between-individual and between-place variation - a multilevel tutorial. Environ Plan A 1997; 29: 585-609.

27 Cubbin C, Santelli J, Brindis C, Braveman P. Neighbourhood contexts and sexual behaviours among adolescents: findings from the National Study of Adolescent Health. Perspect Sex Reprod Health 2005; 37: 125-134.

28 Smith T. Influence of socio-economic factors on attaining targets for reducing teenage pregnancies. BMJ 1993; 306: 1232-1235.

29 Lee E, Clements S, Ingham R, Stone N. A Matter of Choice? Explaining National Variation in Teenage Abortion and Motherhood. York, UK: Joseph Rowntree Foundation, 2004.

30 McLeod A. Changing patterns of teenage pregnancy: population based study of small areas. BMJ 2001; 323: 199-203.

31 Wilkinson P, French R, Kane R, Lachowycz K, Stephenson J, Grundy C, et al. Teenage conceptions, abortions, and births in England, 1994-2003, and the national teenage pregnancy strategy. Lancet 2006; 368: 1879-1886.

32 Wellings K, Wilkinson P, Grundy C, Kane R, Jacklin P, Stevens $\mathrm{M}$, et al. Evaluation of the Teenage Pregnancy Strategy: Annual Synthesis Report No. 2. 2002. London, UK: London School of Hygiene and Tropical Medicine, University College London, British Market Research Bureau, 2003.

33 French R, Mercer C, Kane R, Kingori P, Stephenson J, Wilkinson $\mathrm{P}$, et al. What impact has England's teenage pregnancy strategy had on young people's knowledge of and access to contraceptive services? J Adolesc Health 2007; 41: 594-601.

34 Diamond I, Clements S, Stone N, Ingham R. Spatial variation in teenage conceptions in South and West England. Journal of the Royal Statistical Society Series A 1999; 162: 273-289.

35 Field J, Johnson A, Wadsworth J, Wellings K. National Survey of Sexual Attitudes and Lifestyles. Colchester, UK: The Data Archive, 1990

36 Wadsworth J, Field J, Johnson AM, Badshaw S, Wellings K. Methodology of the National Survey of Sexual Attitudes and Lifestyles. Journal of the Royal Statistical Society Series A 1993; 156: 407-421.

37 Boyle M, Willms J. Place effects for areas defined by administrative boundaries. Am J Epidemiol 1999; 149: 577-585.

38 National Statistics Office. The 1991 Census of England, Scotland and Wales. London, UK: HMSO, 1993.

39 Townsend P, Phillimore P, Beattie A. Health and Deprivation: Inequality and the North. London, UK: Croom Helm, 1988.

40 Forrest R, Gordon D. People and Places: A 1991 Census Atlas of England. Bristol, UK: SAUS, 1993.

41 Arber S. Class, paid employment and family roles: making sense of structural disadvantage, gender and health status. Soc Sci Med 1991; 32: 425-436.

42 Rasbash J, Browne W, Healy M, Cameron B, Charlton C. MLwiN Version 2.01. London, UK: Institute of Education, University of London, 2004.

43 Rasbash J, Steele F, Browne W, Prosser B. A User's Guide to MLwiN: Version 2.0. London, UK: Centre for Multilevel Modelling, Institute of Education, University of London, 2004.

44 Macintyre S, Ellaway A, Cummins S. Place effects on health: how can we conceptualise, operationalise and measure them? Soc Sci Med 2002; 55: 125-139.

\section{READERS' CONTRIBUTIONS INVITED ON 'A BETTER WAY OF WORKING’}

Continuing in this issue (see article on page 262) is the feature entitled 'A Better Way of Working', the purpose of which is to disseminate service delivery suggestions likely to be of interest and relevance to the Journal's readership.

Readers are invited to submit suggestions based on their own personal experience for consideration by the Journal Editor. Contributions normally should not exceed 250-500 words and should be written in a standardised format responding to the following four questions (or similar): Why was change needed? How did you go about implementing change? What advice would you give to others who might be considering a similar course of action? How did you show that the change had occurred?

All contributions should be submitted via the Journal's online submission system at http://jfprhc.allentrack.net. 